\title{
Analysis of Latin America's Corporations as a Rational Response to The Economic Environment Present in The Region
}

\author{
Part I \\ Corporate Governance: Empirical Characteristics and \\ the Legal Framework
}

\section{Sergio A. Pernice and Mariano Fernandez}

\author{
Universidad del CEMA \\ Av. Córdoba 374 \\ (C1054AAP) Capital Federal
}

Argentina

\begin{abstract}
This is the first of a series of working papers analyzing the basic characteristics of the economic environment in which Latin American Corporations live and the optimal design of incentive programs compatible with such environment. By economic environment we mean the technology that the organizations have access to, the legal framework present in these countries, the macro-economical characteristics, the markets in which they operate (competitors, monopolies, customers, reliability of suppliers, etc.), the nature of their capital markets and in general of the sources of financing for their companies, etc. We
\end{abstract}


could broadly say that any key feature of the economy that has the potential to influence the way business is run in Latin America is part of its economic environment.

The underlying unifying idea in this series is that, unless we have clear evidence to the contrary, corporate practices observed in Latin American firms are rational responses to the environment in which they operate. They are a sort of Darwinian adaptation to such environment. Therefore, much like in biological systems, these characteristics of corporations should be considered optimal in a relative sense. That is, in order to survive in the market, the observed corporate practices should be better that the ones from the competition for the given economic environment. This observation suggests that improvements to the observed practices are indeed possible. In fact, the present series of working papers is in part structured to explore possible improvements. These improvements, however, are not likely to be the simple copy of corporate practices that evolved as an optimal response to the environment of the developed world.

In this first work we present some important empirical characteristics of the Latin American Corporations and the first key aspect of the economic environment prevailing in this region: the legal framework. We show how many of the empirical characteristics presented can be see as optimal responses to the legal framework.

\section{Introduction}

We observe empirically that Latin American corporations, and corporations from emerging markets in general, have policies and practices that to some extent could be considered less advanced than the ones observed in firms from the developed world. For example, the use of well-developed incentive compensation programs is far less widespread in Latin American corporations than for example in US firms. The question becomes then why this is the case. How can we explain this difference? 
During the nineties, when the globalization process took off and corporations from all over the world found themselves competing in a global market, the prevailing thought was that these differences in corporate practices were just some of the ingredients that made developed world corporations more competitive. A corollary of this view was that corporations from emerging markets should imitate the common practices of their competition from developed nations. Multinational corporations that copied their headquarters' corporate practices into their developing world subsidiaries explicitly or implicitly embraced this view.

We can make an analogy between this situation and the technological gap that exists between developed and developing corporations. Corporations from Latin America, as well as from Eastern Europe or South East Asia, found themselves at the beginning of the globalization process with an important technological inferiority in their production processes as compared with their developed world counterparts. They responded to this gap by importing technology and know-how from the developed world. Yet, more than a decade later, the production processes of these corporations do not look like the ones of US corporations. Their methods do not have the same mix of work and capital observed in US firms, where much more technology is used.

The reason of this difference is not that the emerging world corporations could not master advanced technology. The gap is not due to trading barriers to acquire such technology either. Of course there was a technological gap, but such a gap could be bridged and in fact it was, and it continues to be bridged in a large part. The main reason that explains the observed difference is that, given the economic environment that Latin American and US corporations inhabit, the optimal mix between labor and capital is simply different in one place with respect to the other. In particular, the far lower relative cost of labor in the emerging world as compared with the developed world makes the optimal labor/capital mix for the later more inclined towards capital.

Noting the mentioned difference in technology, a casual observer could conclude that emerging market corporations are less competitive than their developed world 
counterparts because their level of technology is inferior. But this would be a mistake. As already mentioned, the lower technology used by firms in emerging markets in their production processes is a rational response to a different economic environment, in particular to the relatively lower cost of labor as compared to capital in the emerging world. This is not to say that firms in emerging markets do not need world class technology. They do, and in fact they acquire it, but they need it in a different proportion than US corporations need it simply because the environment in which they produce is different.

The above explanation for the difference in production technology between developed and emerging-world firms has a direct parallel in many differences between the corporate practices observed between these corporations. In fact, the analogy is closer than we might think. We view corporate practices, and in particular incentive programs, as technological products. The purpose of this subtle technology is to increase our ability to pursue ever more complex cooperative projects and organizations. This is, to align the (a priory miss-aligned) interests of the individuals that form these organizations.

The view that we want to present in this work regarding Latin American corporations is that, although "the underlying nature of things" is the same all over the world, different economic environments prevailing in different places induce different optimal corporate practices for firms. By the "underlying nature of things" we mean self-interested individuals that only under certain conditions find it in their advantage to work cooperatively with others. The economic environment in which they work makes these conditions more or less likely. And the contracts that help to align their interests need not be the same in different environments.

According to this line of thought, and repeating what was expressed in the Abstract, we will assume that, unless we have clear evidence to the contrary, corporate practices observed in Latin American firms are rational responses to the environment in which they operate. They are a sort of Darwinian adaptation to such environment. Much like in biological systems, these characteristics of corporations should be considered optimal in a 
relative rather than absolute sense. That is, in order to survive in the market, the observed corporate practices should be better that the ones from the competition for the given economic environment. This observation suggests that improvements to the observed practices are indeed possible. In fact, the present work is in part structured to suggest possible improvements. But these improvements are not likely to be the simple copy of corporate practices that evolved as an optimal response to the environment of the developed world.

This work is organized as follows: in section 2 we provide an empirical description of corporate governance in Latin America where we shown that Latin American companies are fundamentally different from the textbook picture of a modern corporation. In section 3 we try to make theoretical sense of the empirical data. While many people attribute these differences in corporate governance to "cultural" reasons, we prefer a different approach. We will make a list of the main theoretical constructs underlying our understanding of the modern, widely held corporation, and we will point out relevant underlying hypotheses of these theoretical constructs and discuss whether and how such hypotheses apply to Latin America. In section 4 we analyze the legal framework in the region. As we will show, this is one very important factor that help explain characteristics of Latin American companies such as the level of ownership concentration we observe. Finally, in section 5 we conclude. 


\section{Empirical Description of Corporate Governance in Latin America}

The textbook picture of the modern corporation, and by far the most studied structure of companies in academic, as well as practitioner's literature, corresponds to those firms in which ownership is dispersed between small shareholders while control is concentrated in the hands of managers. This form of corporation, prevalent in the United States, was the focus of interest of the 1932 classic "The Modern Corporation and Private Property", by Adolph Berle and Gardiner Means. Since then, this organizational structure has had enormous direct and indirect influence in the development of financial-economic theoretical constructs. For example, Portfolio Theory and Asset Pricing Theory are both based on the assumption that rational investors diversify their investments, which, if true, would imply dispersed ownership of corporations. Similarly, Agency Theory was born motivated by the analysis of conflicts of interests between disperse owners and management ${ }^{1}$. However, Latin America is a region where such form of corporation is rare, to say the least. In fact, recent studies on this subject have shown that disperse ownership is rare all over the world, except precisely in those countries were the theoretical developments took place (mostly US). The following figure summarizes the concentration of ownership in leading companies in thirty countries of the world ${ }^{2}$. The bars show the average percentage of common shares owned by the 3 largest shareholders in the ten largest, non-financial, privately-owned, domestic firms in a given country by 1995.

\footnotetext{
${ }^{1}$ Jensen, M. and Meckling, W, "Theory of the Firm: Managerial Behavior, Agency Costs, and Ownership Structure", Journal of Financial Economics 3 (October 1976): 305-60.

${ }^{2}$ The data we present in this section comes mainly from La Porta, R., López de Silanes, F., Shleifer, A. and Vishny, R., "Law and Finance", Journal of Political Economy, 106 (6), (1998): 1113-1155; and La Porta, R.; Lopez-de-Silanes, F.; and Shleifer, A., "Corporate Ownership around the World", Journal of Finance, April 1999, v. 54, iss. 2, pp. 471-517.
} 


\section{Ownership of the 3 Largest Sharehoders}

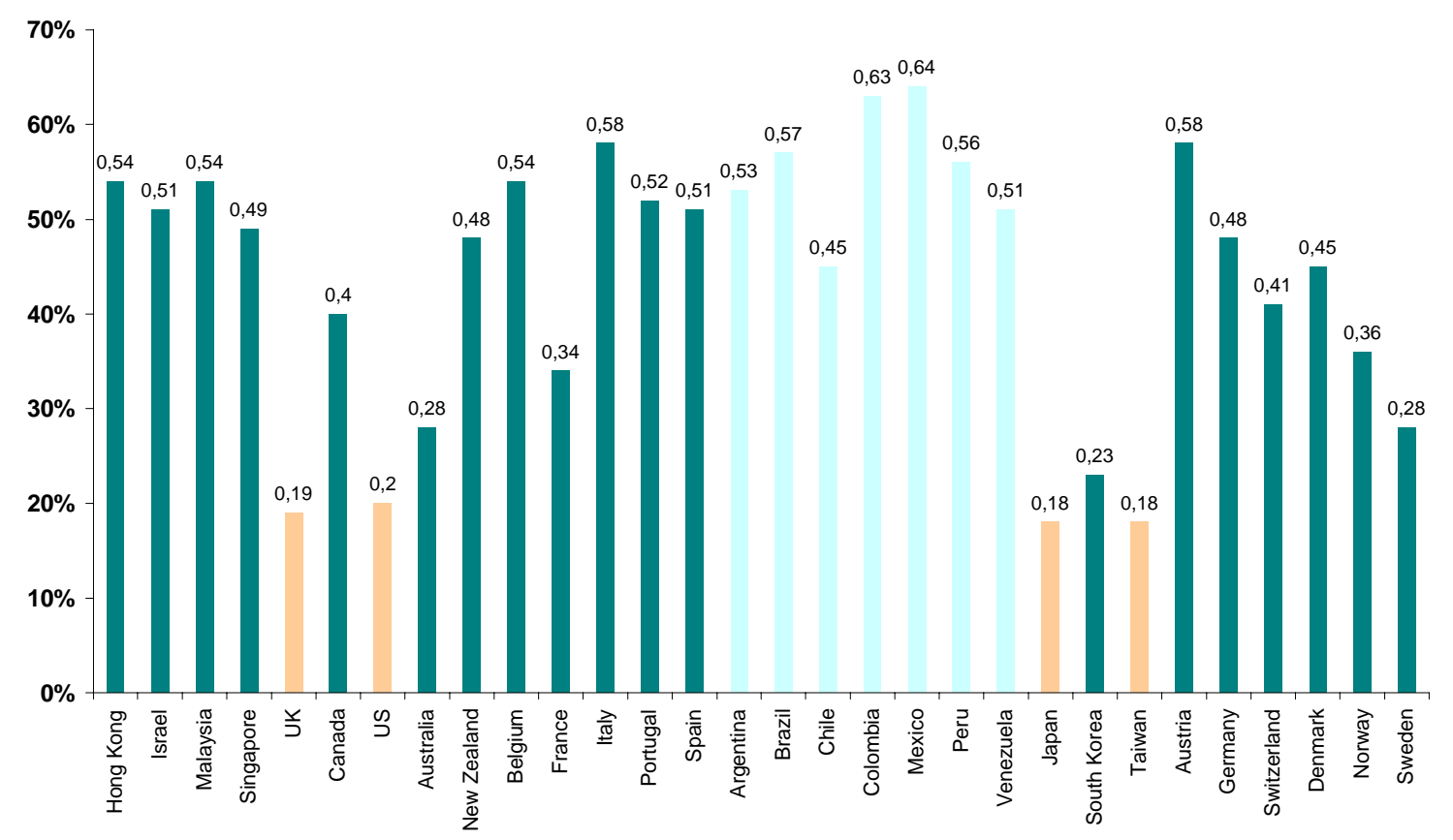

As we can see, the US and UK are the exception, not the norm. Even in those countries, the three largest owners own on average around $20 \%$ of the shares, which is far from the picture of a completely dispersed ownership. But in most of the rest of the world, an in particular in the Latin American countries of interest in this study, more that $50 \%$ of the shares are owned by the three largest shareholders! It is obvious that the driving economic forces that shape the prevalent organizational structures of firms in the US and UK are not the same as the ones shaping organizational structures of firms in our region.

Unfortunately there is almost no academic literature, at least of the economic approach, dealing with the issue of corporate governance in Latin America. In fact, there is very little literature on this issue devoted to countries other than the US ${ }^{3}$. Published research on the subject of executive compensation is even scarcer. After all, executive compensation is mainly designed to align the interests of executives and owners. But the kinds of misalignments of those interests that executive compensation tries to resolve, crucially

\footnotetext{
${ }^{3}$ Notable exceptions are the papers referenced in footnote 2, where many countries of the world are considered.
} 
depend on corporate structure. In disperse ownership structures, where management and control are separated, the problem arises mainly because it is very costly for those owners (who have only a small portion of their portfolio attached to a given company) to closely monitor the managers. It is then more efficient to compensate managers with equity to align interests, even though this form of compensation exposes managers to unwelcome risks beyond their control. Similarly, understanding corporate structures in Latin America is a prerequisite for identifying potential sources of misalignment between owners and managers in the region. Once again, this is mainly uncharted territory. The goal of present paper is to initiate a systematic analysis of corporate structure (or corporate governance) in Latin America.

What follows is a detailed empirical description of Latin American companies. Then in section 3, we attempt a first draw at a theoretical understanding of the Latin American corporation.

In the following figures, the only Latin American countries represented are Argentina and Mexico, but as we will see in section 4, the picture that emerges is representative of the Latin American corporation in general.

If Latin American companies are not widely held, it is then of interest to know what type of owner tends to be the controlling shareholder. Using $20 \%$ of shares owned as the criteria for control (which, by all standards, is a very strict definition of control), the controlling shareholders of the largest (by stock market capitalization of equity) Latin American corporations are families. This is perhaps not surprising for people from the region, but clearly far from the standard textbook picture. 


\section{Control of Large Publicly Traded Firms as of 1995 \\ ( $20 \%$ criterion)}

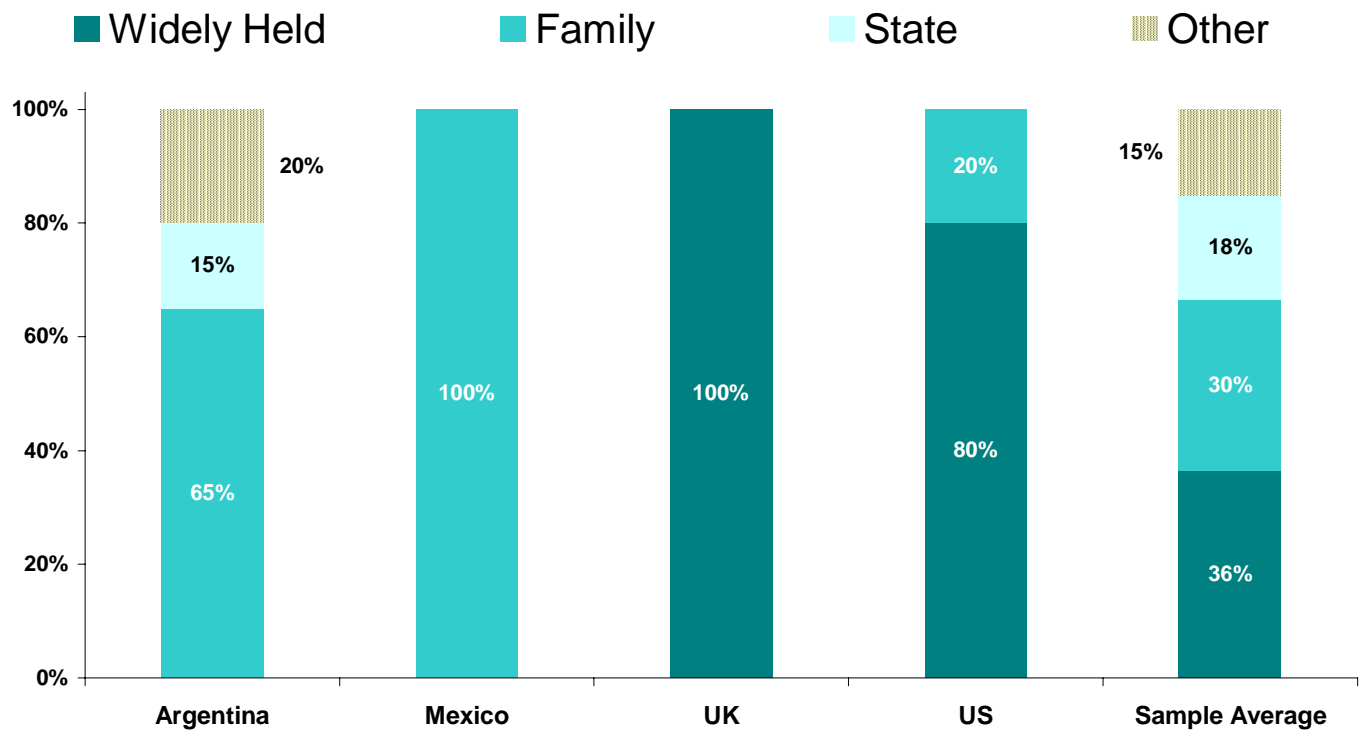

The "other" category refers to ownership by a widely held financial or non financial corporation, or to other less easily identifiable owners. The "Sample Average" refers to the arithmetic average of 27 countries studied in the second paper of reference 2 (Argentina, Australia, Austria, Belgium, Canada, Denmark, Finland, France, Germany, Greece, Hong Kong, Ireland, Israel, Italy, South Korea, Japan, Mexico, Netherlands, New Zealand, Norway, Portugal, Singapore, Spain, Sweden, Switzerland, UK, US).

As we can see, although large firms in the US and UK are mostly widely held, the largest Latin American companies are overwhelmingly controlled by families. Families are in fact the second largest kind of owners in the sample, meaning they are important all over the world. But this trend is particularly marked in Latin America.

It might be argued that this difference could be explained, at least in part, by the sheer size of the companies involved. The 20 largest firms in the US and UK have a much larger market capitalization than the 20 largest firms in Latin American countries. Perhaps when the size of a company increases, the tendency to diversify becomes stronger. To address this issue, the following figure shows the type of owner of ten medium size firms (market 
capitalization above, but near, $\$ 500$ million) from the countries in the list. The criterion for control remains the same (20\% of shares).

\section{Control of Medium Size Publicly Traded Firms as of 1995}

( $20 \%$ criterion)

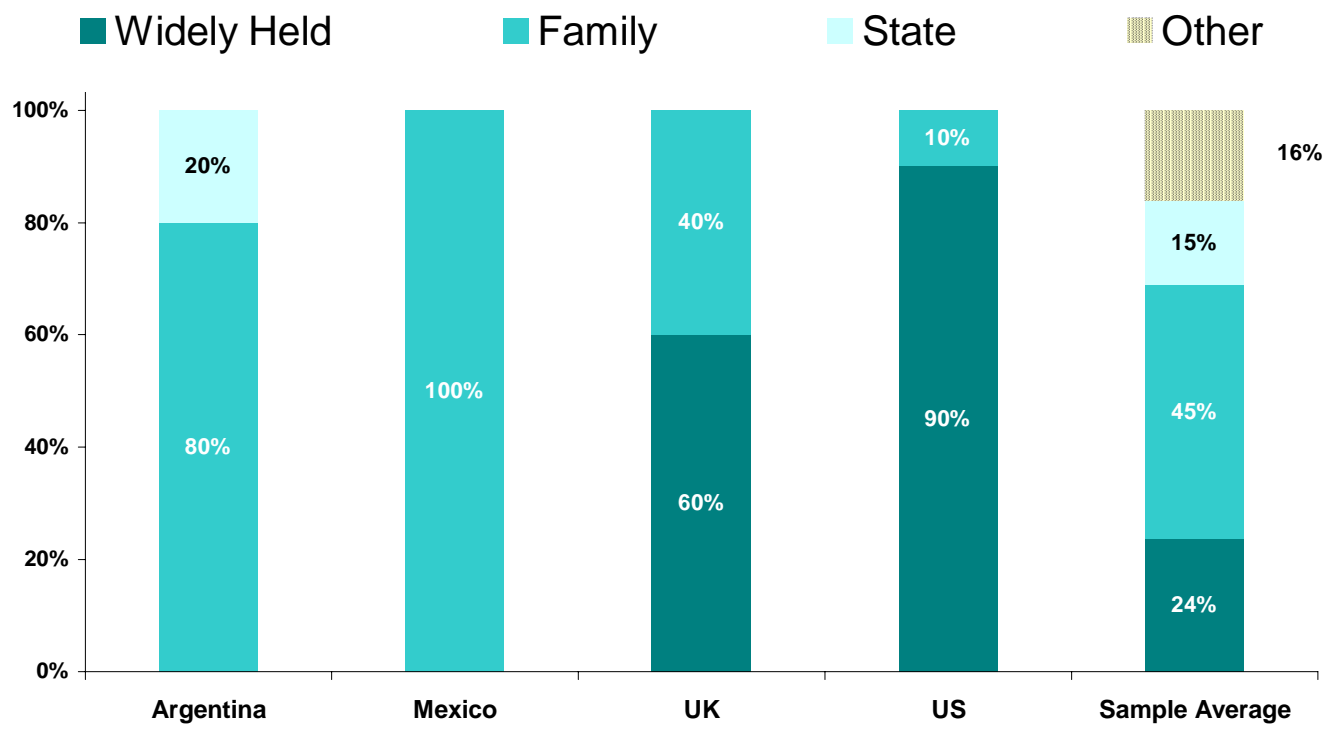

As we can see, it is indeed the case that family ownership becomes more important when smaller firms are considered. Families control $45 \%$ of medium size companies but only $30 \%$ of the largest ones for the entire sample. Even in the UK, with the totality of its 20 largest firms widely owned, $40 \%$ of medium size firms are owned by families. However, it remains valid to say, even controlling for size, that the frequency of family ownership in Latin America is one of the largest in the world. This fact is perhaps the most characteristic feature of Latin American ownership. 
The above figures use a definition of control of ownership of $20 \%$ of shares or more. It is interesting to inquire to what extent families are willing to ensure control, even at the cost of lack of diversification. The next figure shows the average percentage owned by the controlling family in those firms that meet the $20 \%$ criteria for a controlling family among the largest companies in the respective countries at the end of 1995 . Note that only a small proportion of the US largest companies meet this criteria, while all the largest companies in Argentina and Mexico do so.

\section{$\%$ of Market Value Owned by the Controlling Family}

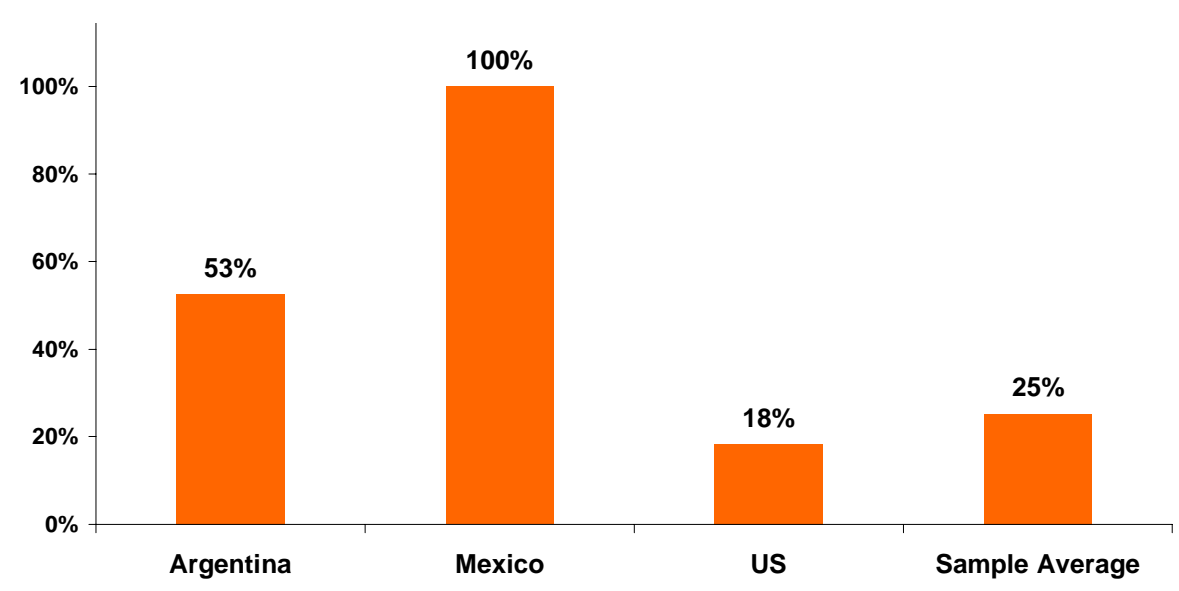

In the figure above, the shares of all family members with the same last name are added. This explains the difference between the present $100 \%$ of shares owned by the controlling Mexican families versus $64 \%$ in the figure on page 6.

We see that Latin American families who control companies take the control issue extremely seriously. Indeed, they leave virtually no chance of a takeover that would threaten their control. By contrast, in the US and in the sample in general, the controlling families do not spend resources ensuring such a large proportion of shares.

The next figure shows that, in addition to owning a large proportion of shares, family members are active in management in the firms they control. The figure shows how often a member of the controlling family is the CEO, the Chairman, the Honorary Chairman, or the 
Vice-Chairman of the firm that the family controls. Again, the twenty largest firms controlled by a family who owned at least $20 \%$ of the shares at the end of 1995 are considered.

\section{Family Involvement in Management}

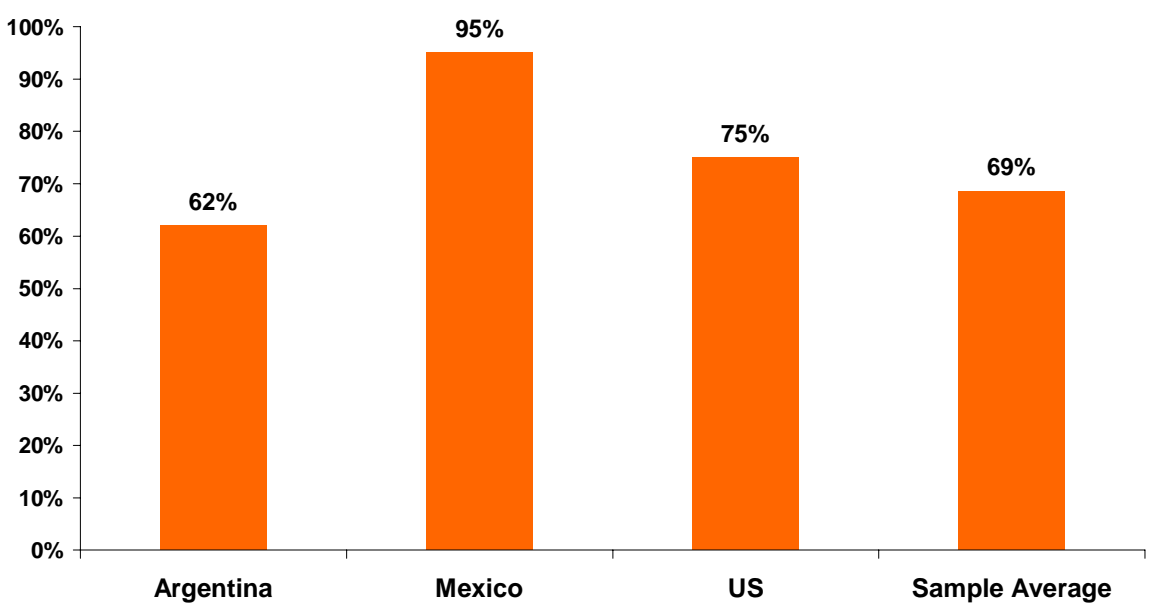

We see that most of the controlling families are involved in management. In this way, they reduce conflicts of interests between owners and managers. This is one of the possible advantages of concentrated ownership. In Argentina, although more than half of the controlling families gets involved in management, they do so less often than the average of the sample. This can perhaps be explained by the abrupt change of rules that took place in this country during the nineties. The country went from a very closed economy where families run their companies almost without competition, and therefore no world class managerial expertise was necessary to survive, to an economy open to external competition. The fastest way for some families to adapt to the new environment was perhaps to buy external managerial expertise.

The data we have just reviewed shows that Latin American corporations are characterized by powerful families that tightly control their firms. They value so much the control of their companies that they are willing to spend a large proportions of their capital ensuring unchallenged control, even at the large costs of lack of diversification that this practice implies. They are not only the owners but also the managers of their firms. 
Given the power they have, controlling families have incentives, and indeed the means, to find ways to effectively expropriate minority shareholders. Do they do that? One potential way to reduce the chances of such an expropriation would be presence of other large shareholders that might have incentives to monitor the controlling family. In the following figure we ask how often, in a company that has a controlling family with $20 \%$ of shares or more, there is no other shareholder that owns at least $10 \%$ of shares.

\section{Probability of Non Secondary Shareholder Owning at Least $10 \%$ of Shares}

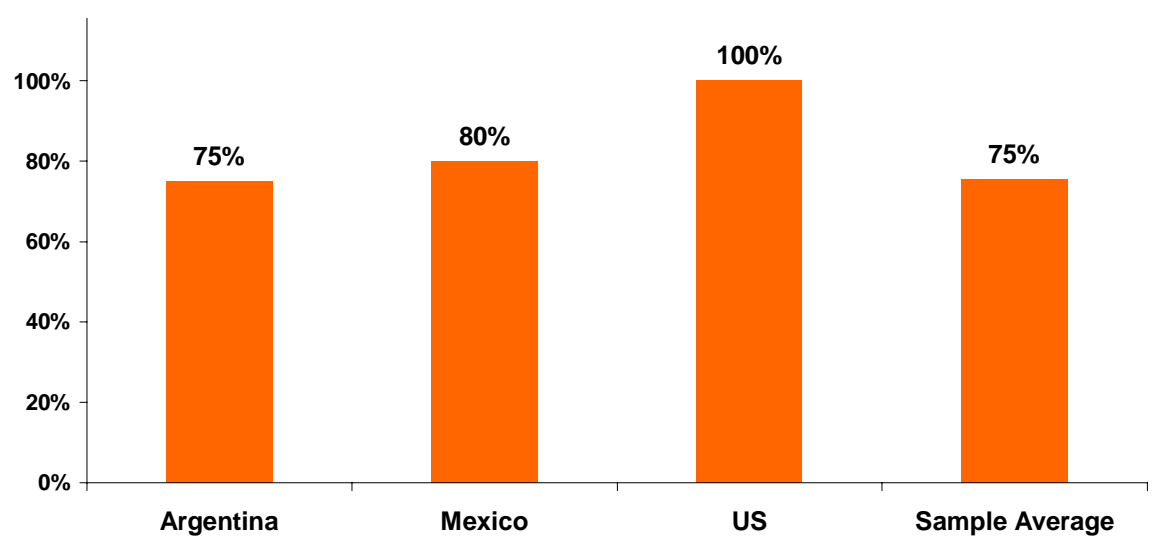

We see then that if there is a solution to the conflict of interests between the controlling family and minority shareholders, another large shareholder is not the one. In fact, we believe that in Latin America this conflict has not found a solution. And that having no solution not only is consistent with the level of development of the financial markets in those countries (topic to be discussed in a forthcoming paper) but is the equilibrium response to the economic environment in which these firms operate.

\section{Making sense of the empirical data}

We have shown that Latin American companies are fundamentally different from the textbook picture of a modern corporation. Many people attribute these differences to 
"cultural" reasons. We prefer a different approach. In order to make sense of these differences we start by listing the main theoretical constructs underlying our understanding of the modern, widely held corporation. We will point out relevant underlying hypotheses of these theoretical constructs and discuss whether and how such hypotheses apply to Latin America.

What follows is an analysis of the theoretical building blocks upon which the understanding of the Modern Corporation is based.

\section{Efficient Markets Theory}

Research shows that stock prices follow a random walk, with no discernible predictable patterns that investors can exploit. Such finding is taken to be evidence of market efficiency. In other words, market prices reflect all currently available information. Only new information will move stock prices. If people's expectations are on average correct, with respect to those expectations, new information is equally likely to be good or bad news.

Market participants distinguish between three forms of market efficiency. We focus our attention in the so-called "semi strong" form, which claims that all publicly available information is rapidly reflected in the prices of securities.

We believe that this form of efficiency applies to the Latin American capital markets. We believe so not only because many studies (mostly unpublished) are consistent with this hypothesis, but also because the underlying assumptions are very robust. Not assuming some form of market efficiency is similar to proposing that a $\$ 100$ bill on the sidewalk, with many people walking around, will last for long.

This does not mean to say that these markets are liquid, or that the same number of analysts study firm performance in Latin America than for example in the US. In a paper in this 
series dedicated to the financial markets in the region we will see that this is in fact not the case. Therefore the mechanisms that make markets efficient are less lubricated in Latin America than in other markets. But the lower level of proficiency of these mechanisms, we claim, is simply the result of the optimal level of resources justified by the size of the markets.

\section{Portfolio Theory}

Portfolio Theory was mainly developed by Markowitz to try to answer the question of how a rational, risk averse individual will invest her money. In the simplest one-period version of the theory, the future evolution of a stock is characterized by an expected return and an expected volatility. The election between stocks is based on those two parameters and covariances between stocks. Risk-averse individual will try to maximize expected return for a given level of volatility. This leads to a set of "efficient portfolios" among which the individual chooses. Typically these portfolios are well diversified (i.e., the proportion of capital invested in each stock of the portfolio is small), and passive. The relevant measure of risk of a given stock for an investor holding a given portfolio ends up being its covariance with such portfolio, not its variance.

Underlying this theory are various hypotheses, and many studies have been dedicated to the analysis of the changes in the conclusions of the theory that arise when one relaxes one or more of theses hypotheses. In general, the conclusions of the theory are robust against the weakening of these hypotheses. We need to pay special attention here to one of these underlying hypotheses: the zero cost of diversification. In practice there is some cost to diversification since the bid-ask spread is not the same for all stocks, but the theory remains robust as long as such transaction cost is not too large. It happens to be the case that in practice this cost is not too large so everything seems to be OK.

On the other hand, the data shown in the figures above is very persuasive. If the three largest shareholders of the ten largest corporations own on average more than $50 \%$ of the 
stock, if the controlling family owns in fact much more than that and in addition gets involved in management, chances are that controlling shareholders are not well diversified. Why would this be so? The hypothesis that investors all over the world and in particular in Latin American countries are just irrational, and only investors in the US, UK and a few other countries are rational seems unacceptable. There must be some other costs to diversification, or, what is the same, there must be some big advantages to concentration that justify for Latin American owners this notorious lack of diversification. The tradeoffs between risks and rewards that Latin American controlling families face are perhaps not well described by the hypotheses of Markowitz's theorems. They seem to fall short of capturing, for example, the opportunities to gain extraordinary rewards associated with concentration of ownership in the economic environment in which they play. This leads us to inquire about the nature of the economic environment in Latin American countries. This is the topic of the last section of this paper.

\section{Asset Pricing Theory}

The Capital Asset Pricing Model makes some additional assumptions besides the ones made in Portfolio Theory. For our purpose, the relevant assumption that will have to be analyzed in detail in order to understand Latin American corporations and markets is again the zero cost of diversification.

But Asset Pricing Theory plays a fundamental role in assessing the cost of capital (or the opportunity cost of capital), which in turn plays a fundamental role in evaluating the Net Present Value of projects. If some hypotheses in which this theory is based do not necessarily apply to Latin American firms, can we say that the standard way of computing the cost of capital is still valid for them? This issue, interesting as it obviously is, goes beyond the purpose of the present work. 


\section{$\underline{\text { Agency Theory }}$}

In the economic literature, it is normally assumed that people act in their own self-interest. There are many situations in which, in order to achieve her goals, an individual needs to hire another individual to act as her "agent". But asymmetries of information usually develop subsequently to the signing of the contract. For example, if the owner of a firm hires a manager, she may be unable to observe how much effort the manager puts into the job. Anticipating the development of such informational asymmetries, the contracting parties seek to design a contract that mitigates the difficulties they cause. The branch of economics called Agency Theory deals with the problem of the design of the optimal contract. The contracting problem that attracted the major attention and to which most studies have been devoted is the one between disperse owners (shareholders) and concentrated managers, in accordance with the rational behavior of investors suggested by Portfolio Theory.

For Latin American firms we believe that the fundamental problem of Agency Theory, that is, the design of the optimal contract between self-interested individuals, is as relevant as for American firms. But the particular example of a contractual relationship between dispersed owners and concentrated managers is not so relevant because, as we have seen, ownership is not dispersed.

A contractual relation whose analysis is relevant for the typical Latin American firm concerns the relationship between controlling families and minority shareholder. As we mentioned earlier, given the power they have, controlling families have incentives, and means, to find ways to effectively expropriate minority shareholders. As we will see shortly in this section, this state of affairs with one controlling family is the equilibrium response to the environment in which Latin American firms operate. A side effect of this is the emergence of these incentives and means in the controlling family to effectively expropriate minority shareholders. In turn, the equilibrium response to this side effect is that comparatively few people will be willing to put themselves in the situation of minority 
shareholders, and the few who do so will accept such a position only at a discount. This discount reflects the marginal (minority) investor's expectations of such expropriation. In another paper in this series which deals with the financial markets in Latin America, we will see that the characteristics of these markets are consistent with this interpretation.

Another contractual relationship whose detailed analysis is relevant for Latin American contracts is the incentive compensation contracts for high level managers that do not belong to the controlling family. The interests of those managers are not necessarily aligned with those of the majority shareholders. It is true that those shareholders have powerful incentives to monitor those managers, and through their actual involvement in management they surely have also the means for some level of control. But in order to create a compensation contract free of "influence costs" and ambiguities, it is in both parties' interest to compensate top level managers in terms of an equity-based contract. However, as we will see in the another paper in this series, the value of equity is highly influenced by macroeconomic conditions beyond managers' control. In addition, these conditions change so dramatically in short periods of time, that standard equity contracts are not viable. We will dedicate one paper in this series to explore the feasibility of filtering out such macro noise, so that one could in principle base a contract on the value that managers actually add to the company, "clean" of such noise.

\section{The Theory of the Firm 4}

In a market economy, an individual who believes to be good at some productive activity has incentives to buy the resources with which he can pursue such activity. He may believe to be good at it because he may posses specific knowledge relevant for pursuing such activity. He then has incentives to buy the appropriate resources because, combined with his specific knowledge, he can produce goods that he can sell at a price higher than his costs. We see then that markets automatically resolve the problem of assigning economic

\footnotetext{
${ }^{4}$ Jensen, M. "Foundations of Organizational Strategy", Harvard University Press, 1998. Brickley, J.; Smith, C.; and Zimmerman, J. "Managerial Economics and Organizational Architecture", Second Edition, McGrawHill Irwin, 2001.
} 
resources to the person with the relevant specific knowledge. This market mechanism works as long as private property rights are well defined, well enforced, and readily exchangeable. The incentives the individual has to use his specific knowledge in productive activities arise from the fact that, through the existence of private property rights, he bears the wealth effects of his decisions. Ronald Coase won his Nobel Price because he noted that for this market mechanism to work, in addition to private property rights, the transaction costs in the market should be sufficiently low; and they are not always so.

Much economic activity occurs within firms, where administrative decisions rather than market prices are used to allocate resources. Administrative decisions are in general not very efficient at allocating resources to the person with the relevant specific knowledge, nor are they efficient at generating in this person the incentives to use his knowledge productively. These inefficiencies are organizational costs associated with firms. However, the very fact that firms exist suggests that these costs should be smaller than the transaction costs associated with producing the same goods through pure market transactions. If it were not so, competition would have exterminated firms as a way to organize production. The Theory of the Firm studies the organizational costs associated with firms and how to structure organizations in order to reduce such costs (for example, through a well-designed compensation program).

The Theory of the Firm relies heavily on Agency Theory. The optimal way to structure an organization of self-interested individuals depends on the ability of the underlying contracts among these individuals to align their interests. In fact, it is useful to think of the firm as a set of contracts. These contracts form the structure of the organization or the organizational architecture. Ultimately, the efficiency of a given organizational architecture in terms of aligning incentives reduces to the good design and consistency of three pillars: 1) the mechanism used to assign authority in decision making (who has the authority to make what decisions); 2) the compensation policy; and 3) the performance evaluation system. 
The underlying idea is that good companies assign authority in decision making in such a way that the responsible for a given decision should posses the relevant information to make it productively. However such individual should be compensated and evaluated in such a way as to generate the appropriate incentives to make such decision in a way that maximizes firm value.

The organizational architectures we see in Latin America are in general very different from what we see in the US. For example, decision making tends to be more centralized in LA than in the US, and compensation practices are different as well. However, we believe that, while the specific results might be different, the Theory of the Firm as a theoretical approach to understanding organizational architecture is as correct in LA as it is in the US. A defining feature of this approach that brings a powerful perspective to analyze organizations, is the proposition that the structures of firms are equilibrium responses to the constraints they face. It is likely that the noted differences in architecture respond to differences in the economic environments in which these firms operate. In the last section of this paper, we will analyze Latin American firm structures along this line.

$\underline{\text { The Modigliani-Miller Theorem }}$

This is probably the single most important and productive idea in Corporate Finance. This theorem is most commonly stated in the following form:

If:

- There are no taxes

- There are no transaction costs (in particular "contracting costs"), and

- The firm's investment policy is fixed

Then, the value of the firm is independent of its financing policy (for example its level of debt or equity). 
The intuition behind it is simple. The value of a firm is the net present value of its expected cash flows, but, in general, these expected cash flows, as well as the cost of capital, may change under different circumstances. The hypotheses of the theorem are designed to ensure that they won't change. So fixing the expected cash flows and the cost of capital, the net present value is fixed no matter how you split it (in particular, no matter how you split this value into debt and equity). Admittedly, the hypotheses that ensure that the net present value will not change are utterly unrealistic. And in fact one observes empirically clear patterns in the financing policy across firms and industries. These patterns should not be there if the financing policy was irrelevant. So why is this theorem so useful? Its usefulness begins to emerge if one states the theorem in this logically equivalent way:

If the choice of capital structure affects current firm value, then it does so by: Changing tax liabilities Changing transaction (contracting) costs

Changing investment incentives

In another words, the patterns we observe empirically in the financing policy across firms and industries tell us that financing policy does indeed affect firm value. The usefulness of the Modigliani-Miller theorem resides in the fact that it helps us focus on the possible sources of firm value. We should try to understand if the financing policies that Latin American companies typically chose (mostly controlling family's capital and bank lending) affect firm value through some of the Modigliani-Miller mechanisms.

Does the capital structure of Latin American firms affect current firm value through changes in tax liabilities? As we will see in another paper in this series, the macroeconomic conditions change dramatically in Latin American countries in short periods of time. This leads governments to change the rules of the game, in particular the taxing rules, very often. With tax liabilities changing so often in unpredictable ways firms have incentives to try to find ways to hedge such changes as the only way to have some predictability of costs. Some of these ways might not be strictly legal and in this sense, 
owners might want to keep these decisions and the relevant information within the family. In addition, if, as we will see, the legal environment is not very strict, tax evasion might become for many firms a condition for survival, because the competition plays in the same way and they are not punished. Therefore, to have competitive costs, the Nash equilibrium strategy might contain some level of evasion. Again, under these conditions, relying on the family might be a safer way to do business.

Regarding transaction costs, the costs discussed earlier associated with the risks of being a minority shareholder imply that family's capital financing has a lower cost. This helps to explain the ownership concentration. In another words, due to agency costs already discussed, a contractual arrangement of disperse owners that hire managers to run the companies in their behalf is just too costly in the economic environment in which Latin American firms operate. The reduction of these agency costs makes family control a more efficient form of organization in the Latin American environment, even at the expense of having to pay the cost of lack of diversification.

To give an even more dramatic example, let us consider the nature of foreign investment that comes to the region. If family concentration of ownership were due to reasons different form the ones proposed here, as for example "cultural" reasons, then we should expect different ownership structures associated to foreign investment. Foreign firms presumably come to the region with a different cultural background. However, as we will see in another paper in this series, the nineties brought to Latin America a changing form of foreign investment. During the first years of the decade, when globalization exploded and a torrent of foreign investment arrived to the region, the predominant form of investment was trough financial markets, as minority shareholders or through debt financing. But after the Tequila effect, Foreign Direct Investment (FDI) became the predominant form of foreign investment, reaching just under $97 \%$ of net private capital inflow in 1999. In reference the authors find that countries that are riskier, less financially developed and have weaker institutions tend to attract less capital than others, and more of it in the form of FDI. Why? Because FDI is a form of investment that ensures control. And, as local controlling

\footnotetext{
5 "Foreign Direct Investment: Good Cholesterol?", Hausmann, F Arias, IADB, Working Paper N 417.
} 
families seem to know, and foreigners learned after the Tequila effect, control reduces many agency costs that are far more problematic in the economic environment prevalent in Latin America than for example in the US.

Does the financial structure change firm value by changing investment incentives? People are in general risk averse, and this is clearly reflected in the financial markets through the differential valuation of risky securities. But the larger the proportion of your capital subject to a given source of risk, the more risk averse you tend to be with respect to such risk. This is the logic behind Portfolio Theory and the corresponding advantages of diversification. A diversified shareholder has a small proportion of her capital attached to a given company, therefore she is basically risk neutral with respect to the specific risks of such company. From this risk neutrality to specific or idiosyncratic risks of the company is that emerges the investment rule to "take all positive net present value (NPV) projects". Even if a project is very risky, as for example projects in the frontier of technology, if such risk is taken into account in the calculation of NPV and still the project has a positive NPV, the diversified shareholder wants to take such project. If the project goes bad the corresponding company will probably go bankrupt but even this negative scenario is not so dramatic for the diversified shareholder who will loose a small proportion of his capital.

How does the controlling family evaluate very risky project? Since they have a large proportion of their capital attached to the company, they are very risk averse with respect to the firm's specific risks. They may therefore not want to take risky projects because their failure implies the financial collapse of the family. The investment rule for this family may not be correctly described by "take all positive net present value (NPV) projects". They may want to add "except if the project is too risky". Ownership concentration evidently affects investment incentives. The fact that a large proportion of technological projects takes place in the US, and the fact that this country is one of the few in the world where the prevalent form of investment involves true diversification may not be unrelated phenomena. 


\section{$\underline{\text { Economic Darwinism }}$}

In industry, we see economic Darwinism at work as competition weeds out ill-designed organizations that fail to adapt. Competition in the marketplace provides strong pressures for efficient decisions, including decisions regarding compensation policies. If firms adopt inefficient, high-cost policies, competition will place strong pressures on them. But in economic systems, as in biological systems, the efficiency of a form of organization that ensures its success depends on the environment. The economic environment is mainly characterized by: 1) the technology that the organizations have access to (computers, telecommunications, production methods, etc.); 2) the characteristics and stability of the macroeconomic conditions of the country in which the firm operates; 3 ) the markets in which they operate (competitors, monopolies, customers, reliability of suppliers, the characteristics of the financial markets, etc.); 4) the regulations and enforcement of such regulations (taxes, international laws, labor laws, etc.). The rest of this paper deals with this fourth aspect of the environment, concerning regulations and their enforcement.

This concept of Darwinism has important implications to guide the analysis of Latin American firms. First, existing forms of organizations are not random; they are probably the efficient response to the economic environment prevalent in the country in which they emerge. Second, surviving organizations at any point in time are optimal in a relative rather than absolute sense; that is, they are the best among the competition, not necessarily the best possible. Third, if in any given country the environment in which the firm operates changes (for example if technology, competition, regulations or macroeconomic conditions change) then the appropriate organizational structure normally changes as well. Fourth, if at any given point in time we see that the surviving organizations in two different countries have very different structure (as for example ownership structure), then, to understand those differences we should probably focus on the differences in the respective environments in which the firms operate.

These four observations taken together suggest that, although improvements in organizational structures are certainly possible, we should resist condemning prevailing 
structures without careful analysis. Before suggesting major changes, for example in the compensation policies, we should have a good understanding of how the firm arrived at the existing architecture and, more generally, develop a broader perspective as of why specific types of organizations work well in particular settings.

\section{The Legal Framework}

One factor that could help explain the level of ownership concentration we observe in Latin America would be a legal system that poorly protects minority shareholders rights. The legal system acts as an underlying platform in which private contracts take place. The stronger the legal protection for minority shareholders, the greater the number of people willing to sign such contracts. Conversely, if such protection is weak, we should see a small number of contracts of this kind. If there is a small number of people willing to put themselves in the position of minority shareholder, the adaptive response of the firm, the equilibrium form of ownership in such environment, is concentration. The legal environment is therefore a potentially important factor for explaining concentrated ownership. In fact, in reference 2, the authors found a strong negative correlation between concentration of ownership and the quality of the legal protection of investors all over the world. We present here the corresponding data for the Latin American countries of interest in this study. In the figure below, the sample average refers to the arithmetic average of the 49 countries studied in the first paper of reference 2. The countries are: Argentina, Australia, Austria, Belgium, Brazil, Canada, Chile, Colombia, Denmark, Ecuador, Egypt, Finland, France, Germany, Greece, Hong Kong, India, Indonesia, Ireland, Israel, Italy, Japan, Jordan, Kenya, Malaysia, Mexico, Netherlands, New Zealand, Nigeria, Norway, Pakistan, Peru, Philippines, Portugal, Singapore, South Africa, South Korea, Spain, Sri Lanka, Sweden, Switzerland, Taiwan, Thailand, Turkey, UK, Uruguay, US, Venezuela, Zimbabwe. 
The following figure shows an index that measures the level of shareholder rights. The index is formed by adding 1 when: 1) the country allows shareholders to mail their proxy vote to the firm; 2) shareholders are not required to deposit their shares prior to the General Shareholders meeting; 3) cumulative voting or proportional representation of minorities in the board of directors is allowed; 4) an oppressed minority mechanism is in place 5) the minimum percentage of share capital that entitles a shareholder to call for an Extraordinary Shareholders meeting is less than or equal to 10 percent; 6) shareholders have pre-emptive rights that can only be waved by a shareholder' vote. The index ranges from 0 to 6 .

\section{Shareholder Rights}

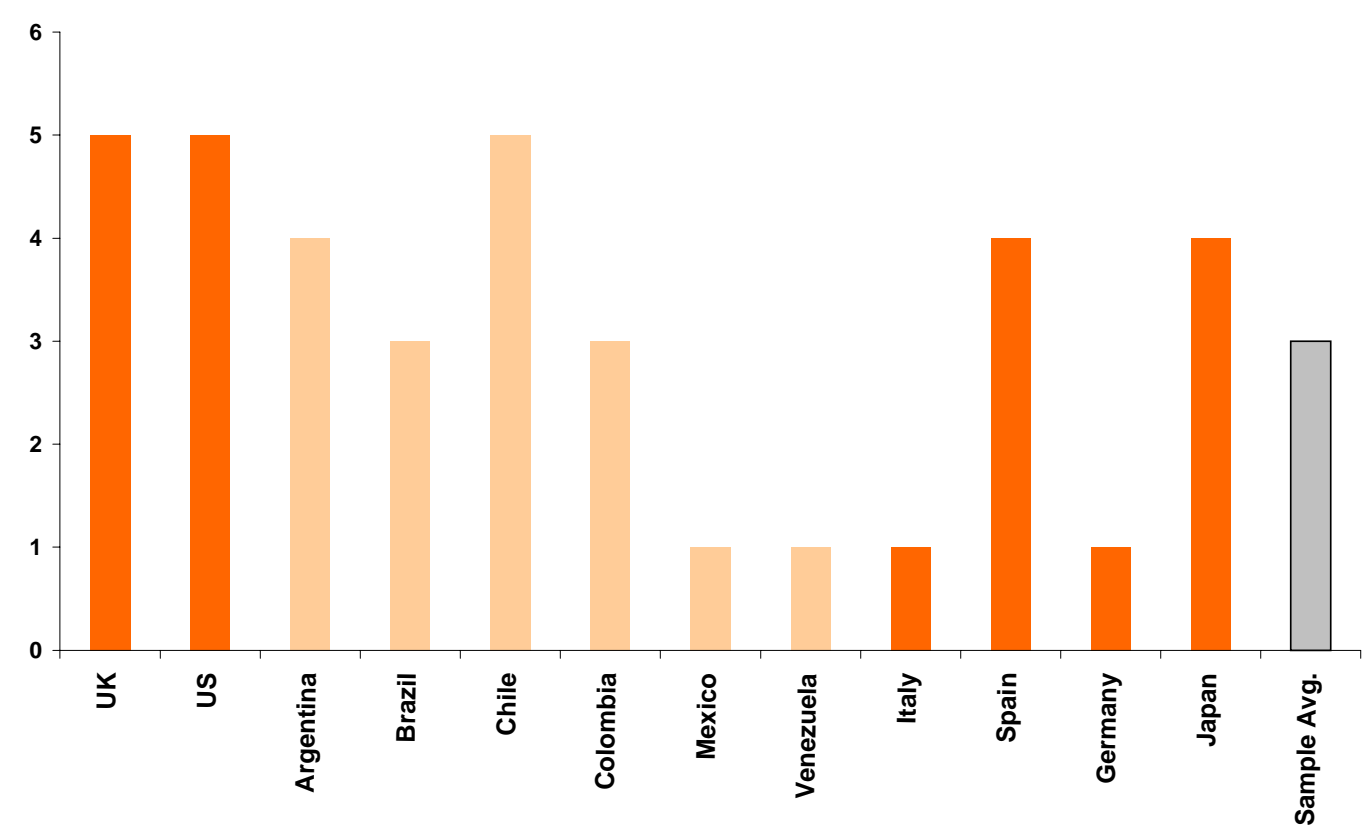

Shareholder rights in Latin America change greatly between countries. And, as a whole, they are not significantly worse than in the rest of the sample (as measured by "Sample Avg."). Therefore, if there is something particularly "Latin American" that would explain the extremely concentrated ownership we see in the region, the content of the law is not it.

Different is the story, however, if we inquire not about what the law says but how it is implemented in practice. The following figures provide measures of the quality of legal implementation. The next figure shows a measure the efficiency of the judicial system, an index produced by the country-risk rating agency Business International Corporation. It is 
an average between 1980-1983. The scale goes from 0 to 10, with lower scores indicating lower efficiency levels.

Efficiency of judicial system

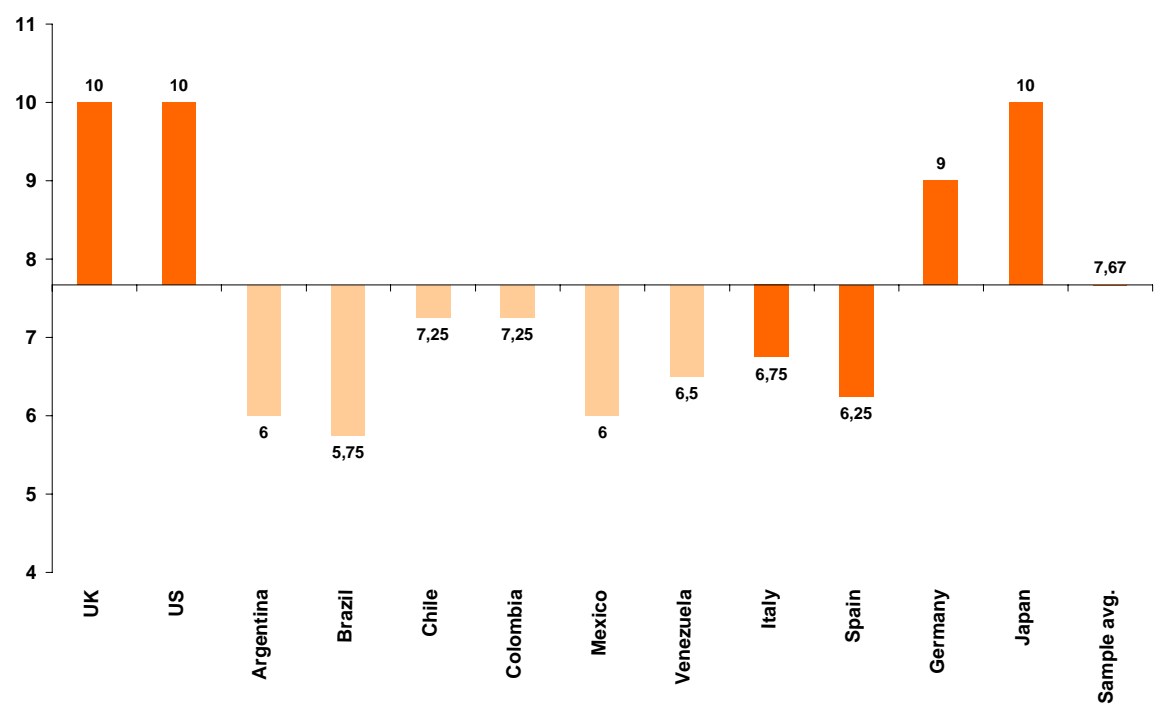

We see that the judicial systems of Latin American countries are significantly less efficient than the sample average. That is, even though minority shareholders may have some rights, when the time comes to enforce those rights this might not be so straightforward in Latin America. Foreseeing these difficulties, people may decide that they do not want to be minority shareholders.

The next figure shows an assessment of the law and order tradition in a given country produced by the country-risk rating agency International Country Risk. It is an average of April and October of the monthly index between 1982 and 1995. Again, the scale used ranges from 0 to 10 . 


\section{Rule of Law}

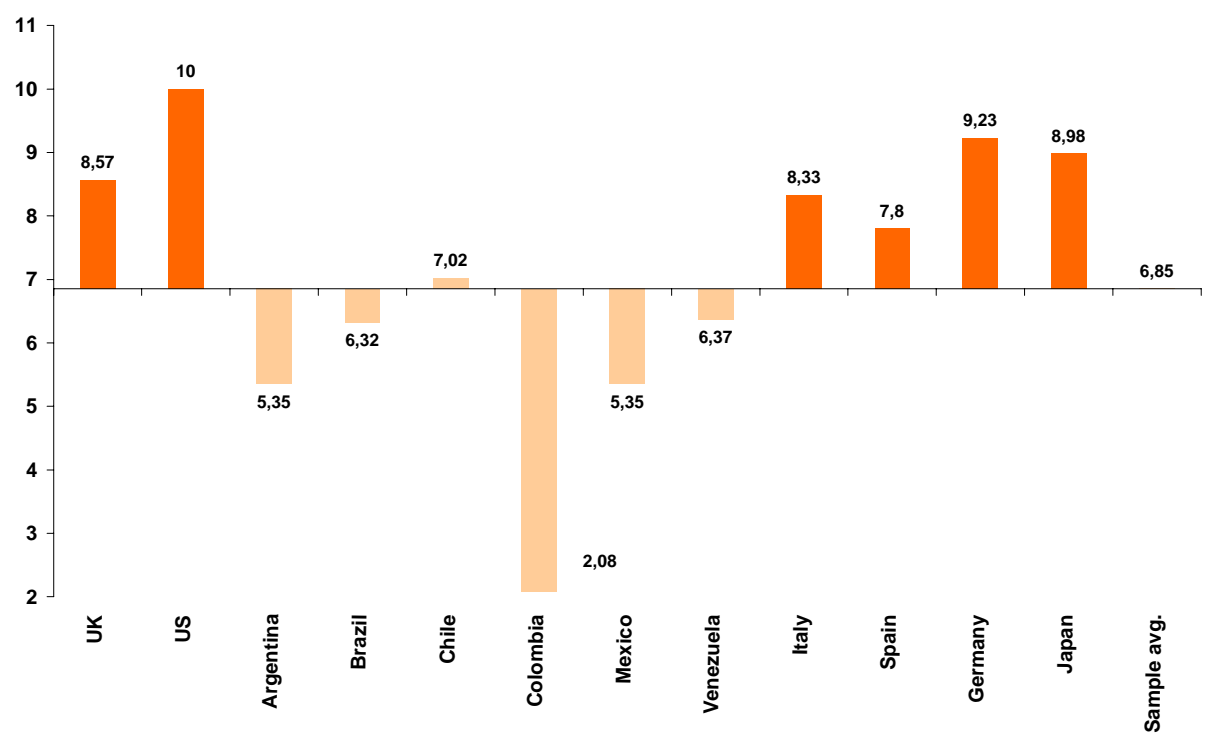

We see once again that Latin American countries do not fear well on average, with the possible exception of Chile.

It is interesting to have an objective index measuring corruption. International Country Risk makes an assessment of the corruption in government. Lower scores indicates "high government officials are likely to demand special payments" and "illegal payments are generally expected throughout lower levels of government" in the form of "bribes connected with import and export license, exchange controls, tax assessment, policy protection or loans". An average of the months of April and October of the monthly index between 1982 y 1995 was taken. The scale goes from 0 to 10, with lower scores for higher levels of corruption. 


\section{Corruption}

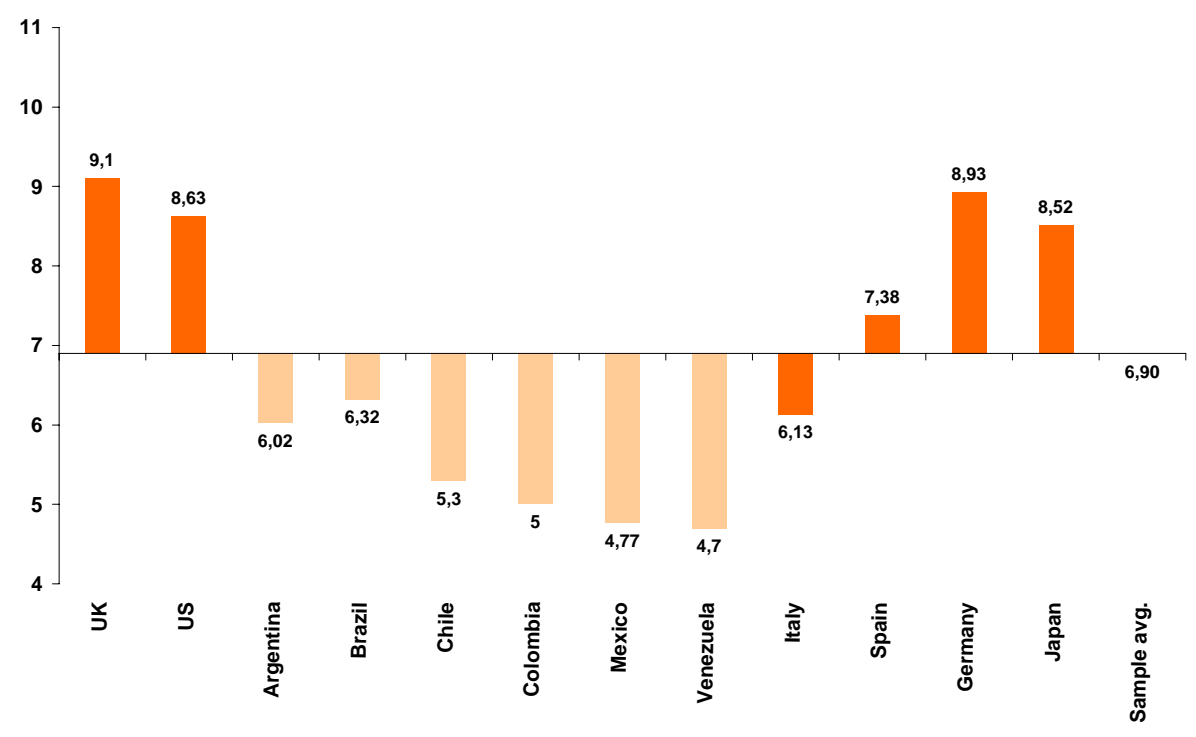

If these are the rules of the game, and you want to play, you probably want to play with the protection of the family.

The same country-risk agency assesses the risk of "outright confiscation" or "forced nationalization" by the government. The next figure shows the average of the months of April and October of the monthly index between 1982 y 1995 . The scale goes from 0 to 10 , with lower scores for higher risks.

Risk of expropiation

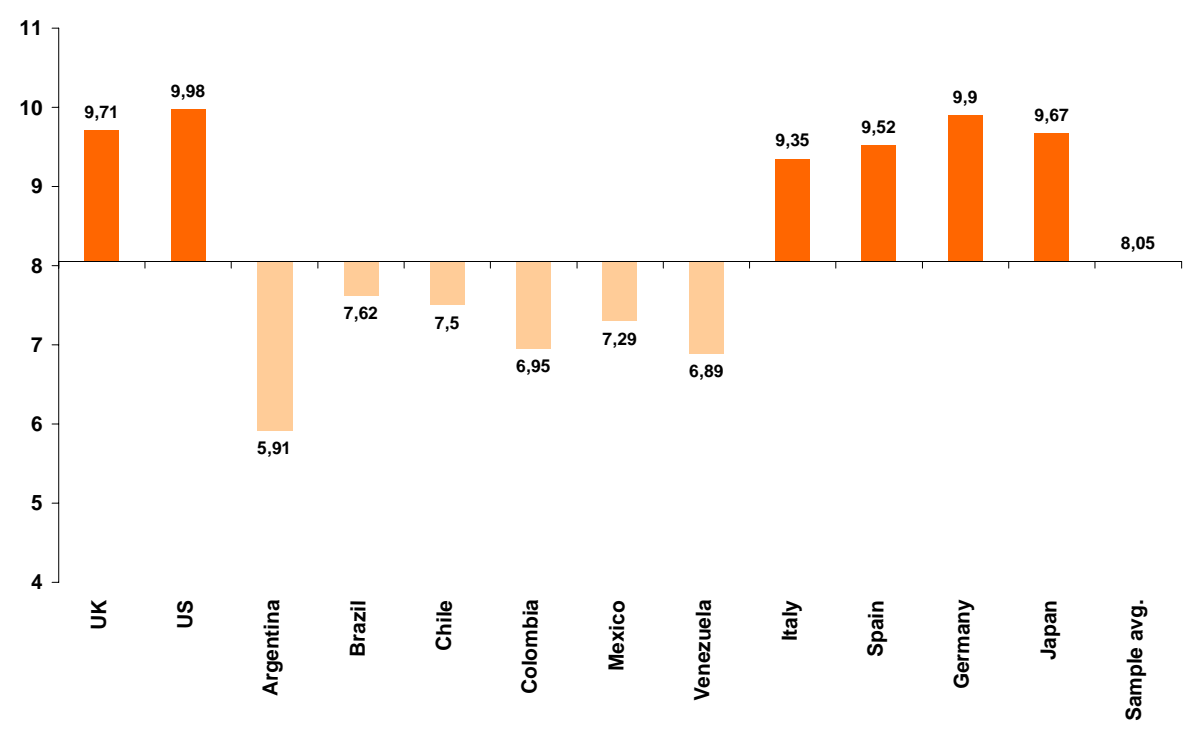


Recent events in Argentina confirm that this is a serious issue in the region. But if there is a large risk of expropriation one adaptive response is that many contracts will take place without government knowledge. Again the best environment for this form of operation is probably a family business.

\section{Conclusions}

We see then that the hypothesis that the Latin American concentration of ownership in the hands of families is an efficient response to the environment in which they operate gives us a powerful perspective. However, as we mentioned earlier, improvements in the organizational structure are indeed possible, and a careful analysis of the Latin American environment can help identify them. In particular, we will see in the next papers in this series that the value of a corporation dramatically depends on the macroeconomic conditions, and that such conditions change very often. Moreover, although small in size and sometimes poor in liquidity, the financial markets in Latin America are nonetheless fairly efficient. Given these two conditions, a particularly potent improvement is therefore possible in incentive compensation contracts: it is imperative to compensate managers for the value they create. As already mentioned, this requires filtering out the macro noise that pervades the value of the company and that is totally beyond manager's control. We will dedicate the last papers in this series to this issue.

\section{Acknowledgements}

One of the authors, S.P., would like to acknowledge William M. Mercer Human Resources Consulting for sponsoring this work. 
